\title{
EL GOBIERNO CARDENISTA DEL DISTRITO FEDERAL DE MÉXICO Y SU PROPUESTA DE PARTICIPACIÓN CIUDADANA
}

\author{
Sergio Zermeño*
}

Fecha de recepción: septiembre de 1999

Fecha de aceptación y versión final: diciembre de 1999

Resumen: En este artículo el autor plantéa los problemas a que se enfrentó la administración de Cuahtémoc Cárdenas (1997-2000), al organizar los comités vecinales de participación ciudadana en el Distrito Federal y al poner en práctica la Ley de Participación Ciudadana hacia principios de 1999. Un punto central está relacionado con las dimensiones óptimas, en términos poblacionales y territoriales, para llevar a efecto la articulación entre las demandas de la ciudadanía y la concurrencia de los equipos gubernamentales para hacer frente a ellas. Se analiza igualmente la forma en que los nuevos aspirantes al gobierno de la ciudad capital de México están planteando superar los errores y las limitaciones del primer trienio perredista en materia de participación.

Palabras clave: Participación ciudadana, descentralización, democracia social, democracia representativa, comités vecina les, consejos zonales.

Abstract: This article reviews some of the main problems faced by the administration of Cuahtémoc Cárdenas during the period 1997-2000 when it was decided to organize neighborhood commitees of citizens' participation in the Federal Distric of Mexico City (DF) and to implement the Law of Citizens Participation of 1999. One of the issues discussed concerns the optimum population and territorial size for the best articulation between citizens demands and local governement. Also discussed are the different proposals through which the new political actors of Mexico's capital are proposing to trascend the mistakes and limitations with respect to participation of the first three years of the PRD local government.

Key words: Citizens'participation, decentralization, social democracy., representative democracy, neighborhood commitees, zoning councils.

\section{PRESENTACIÓN}

En diciembre de 1997 una nueva administración perteneciente al opositor Partido de la Revolución Democrática tomó posesión en el Distrito Federal y en sus delegaciones territoriales, proponiendo como uno de sus objetivos un plan de gobierno asentado en la participación ciudadana y, para ello, en la reorganización de los espacios de participación vecinal y barrial.

El Distrito Federal, capital de la república mexicana, está dividido en 16 delegaciones territoriales de las cuales la mayor; Iztapalapa, congrega a más de dos millones de habitantes (en total el DF cuenta con alrededor de diez millones de habitantes y la zona conurbada que lo rodea con otros diez). Las ideas de la participación ciudadana y de la descentralización administrativa fueron esgrimidas, desde la campaña política de Cuauhtémoc Cárdenas en 1997, como la vía privilegiada para enfrentar los problemas urbanos en condiciones presupuestales reducidas en prácticamente un $40 \%$ con respecto al última administración del PRI (1994-97), partido que ha estado en el poder en México por más de setenta años.

El lema "¡Juntos! gobernaremos la ciudad" fue una pieza clave de esa campaña y trataba de comunicarle a la ciudadanía que, a diferencia de lo que siempre había acon- tecido en este país, ahora, por fin, el ciudadano común y corriente, y no el ciudadano de influencia ni el agente gubernamental, tendría mecanismos eficaces para hacer sentir sus inclinaciones, sus demandas, sus desacuerdos. A la llegada al gobierno del DF en diciembre de 1997, y tomando como referentes una serie de ejemplos latinoamericanos, los encargados de la participación ciudadana, los representantes de la Asamblea Legislativa (un parlamento de la ciudad con funciones acotadas), los partidos políticos, las ONG's, profesionales del urbanismo, intelectuales y simples habitantes del Distrito Federal, echaron a andar una discusión intensa en torno a este tema y fueron derogadas, como primera medida, partes substanciales de la ley de participación aprobada en junio de 1995.

\section{LA NUEVA LEGISLACIÓN Y LA VIEJA}

La primera pregunta es sobre qué bases se creía que una iniciativa de este tipo (una nueva ley), ahora sí, podría tener

* Doctor en Sociología, egresado de la Escuela Práctica de Altos Estudios de París (asociado al equipo de Alain Touraine). Actualmente es investigador del Instituto de Investigaciones Sociales de la Universidad Nacional Autónoma de México y asesor del delegado político de Tlalpan. $凶$ zerser@yahoo.com 
éxito, a sabiendas del fracaso del intento anterior: la elección de consejeros ciudadanos de 1995 que no logró atraer a las urnas ni al $8 \%$ de los empadronados y que por ello mismo condujo a su derogación. ¿Cuál sería esta vez la diferencia substancial?

Al revisar la Ley aprobada en 1995 nos damos cuenta de algo sorprendente: los consejeros ciudadanos, antes de ser electos, en ningún momento estaban obligados a ser conocidos y a dar a conocer sus puntos de vista públicamente; nada los obligaba tampoco a convocar públicamente a la ciudadanía a la que iban a representar. En efecto, la ley preveía que un aspirante a consejero podría pasar a ser candidato si reunía al menos el $4 \%$ de las firmas inscritas en el padrón de su área vecinal. No preveía ningún contacto de discusión pública y colectiva aparte de este acto individual, puerta por puerta, del candidato o de los integrantes de su equipo.

Con esas firmas las candidaturas quedaban inscritas y, dado que se prohibió la adscripción partidista de los contendientes (lo que es una convención en las leyes de participación de muchos países, pero que al combinarse con el proceso absolutamente impersonal descrito), provocó que los electores nunca supiéramos por quién votar o cuál era el sentido de votar por unas opciones irreconocibles y sin programa, como era el caso en la prácticamente totalidad de las candidaturas. Una vez elegidos, pasaban a formar parte de un órgano centralizado y colocado a gran distancia de la ciudadanía: el Consejo Delegacional. Cada uno de los consejeros así elegidos en 1995, representaba a entre treinta y cincuenta mil habitantes, con el agravante de que esos consejeros jamás tuvieron a su alrededor a un comité o a un grupo definido de ciudadanos que tuviera la capacidad de exigir alguna forma de rendimiento de cuentas. Por lo demás, infinidad de comunidades de alta identidad y consistencia en sus referentes territoriales y en sus demandas fueron y electoralmente divididas de manera que la interlocución de esa unidad era atendida, cuando lo era, por dos o más consejeros.

Estas consideraciones y la bajísima votación con que fueron elegidos los consejeros (menos del 10\%) empujaron al nuevo gobierno cardenista, basándose en las experiencias exitosas de América Latina, a apoyar el principio elemental que establece que "para que haya participación ciudadana hay que hacer que los ciudadanos participen"; que si en otros ámbitos de la sociedad y de la política la participación puede ser encargada a los representantes (como es el caso de los partidos y del parlamento), en el caso que nos ocupa el "delegar" funciones en los "representantes" es la muerte de la participación ciudadana.

\section{HACIA UNA NUEVA PROPUESTA DE PARTICI- PACIÓN CIUDADANA}

A partir de ahí todas las iniciativas con que arrancó el nuevo gobierno, la Asamblea y las organizaciones ciudadanas coincidieron en que: 1) la colonia, 2) el barrio, 3) la macro-unidad habitacional y, 4) el poblado, serían los recipientarios legítimos e insustituibles del acto de plantear problemas desde la ciudadanía y de hacer acompañar ese acto con propuestas para la solución realista de esos problemas. En ese nivel pueden expresarse con fuerza tanto los ciudadanos individualmente como los movimientos y organizaciones sociales, las ONG's, las asociaciones políticas, empresariales, religiosas y deportivas. Dependiendo del tamaño de cada una de las dieciséis delegaciones, el número de estas unidades vecinales oscilaría entre cincuenta y trescientas (en total fueron mil doscientas en el DF). Esto estableció una diferencia substancial con la anterior legislación, más preocupada por la "representación" que por la participación de los ciudadanos.

Sin embargo la colonia, el barrio, el poblado o la unidad habitacional son unidades poco homogeneas, pueden ir de los 3 mil a los 30 ó 50 mil habitantes, pero con todo y todo, se convino, esas serían las unidades básicas e insustituibles de la participación ciudadana. En ellas deberían realizarse las asambleas ciudadanas periódicas; en ellas deberían ser elegidos los comités ciudadanos (compuestos proporcionalmente según la votación que recibiera cada una de las planillas contendientes para elegir dichos comités); en su seno deberían elegirse a las mesas o comités según los diferentes temas álgidos de cada una de esas unidades vecinales (seguridad y rendición de cuentas de la policía, agua y drenaje, educación, juventud y recreación, equipamiento urbano, etc.); a una pequeña unidad de 3 mil o 5 mil habitantes correspondería un comité vecinal de 10 miembros mientras que a una unidad de 20 ó 30 mil habitantes corresponderían dos o tres comités con hasta 15 miembros, lo que implicó a su vez que muchas áreas vecinales (colonia, barrio...), debieran ser divididas en unidades más acordes con este ejercicio.

Apareció inmediatamente una dificultad que se amplificaría con el paso de los meses y se manifestaría plenamente después de las elecciones vecinales (unas elecciones que, por las razones que veremos a continuación fueron desesperantemente diferidas hasta el 4 de julio de 1999). Dicha dificultad consistía en que si en promedio cada cinco o diez mil habitantes contaría con un comité vecinal, una delegación media del DF, como Tlalpan (650 mil habitantes), terminaría eligiendo a 130 de estos comités, siendo que en 1995 sólo contó con 22 consejeros ciudadanos (para ya no hablar de la delegación Iztapalapa o de la Gustavo A. Madero que tuvieron que elegir en 1999 entre 200 y 400 comités). Estas magnitudes, por experiencia, hacen inoperante cualquier organismo que se proponga trabajar con todos esos comités (algo así como 16 asambleas de representantes, o parlamentos, para los cerca de diez millones de habitantes del DF).

¡Por qué, si la experiencia dictaba que la descentralización y las magnitudes entre cincuenta y cien mil habitantes eran las mejores, los legisladores y el gobierno decidieron que no había que agregar a esos comités en un piso intermedio por debajo de la Delegación Política y por encima del propio comité vecinal, sin por ello sustituirlo? ¿No hubiera sido acaso más oportuno inventar una figura como la unidad sub-delegacional, con lo que todo el modelo se hubiera acercado a la idea de la descentralización paulatina de funciones y de espacios asociativos?

Recordemos que los problemas de una unidad intermedia de este tipo, llamémosla Unidad Zonal o Sub-dele- 
gacional, tienden a ser más homogéneos, más agregables y más manejables como ha quedado demostrado en aquellas delegaciones que hoy tienen, por ejemplo, la mitad de su territorio en áreas de pueblos rurales y otra buena parte en unidades habitacionales densamente pobladas; dichas unidades sub-delegacionales vuelven además, lo sabemos por experiencia, mucho más racional la articulación entre las demandas de la ciudadanía y las políticas gubernamentales para la solución de esos problemas; al lado de esto, la descentralización en esas unidades zonales podría prefigurar una eventual conformación en unidades municipales de lo que hoy es el DF (forma jurídico política en que está organizado el resto de la república mexicana), y en fin, lo más importante es que permiten que los ciudadanos se reconozcan mejor en un área territorialmente definida, estén al tanto de los problemas y supervisen la obra pública. Así ha sucedido al menos en aquellas grandes ciudades de América Latina y de otras regiones en donde la participación ciudadana se ha combinado con un buen proyecto de descentralización administrativa.

Con lo anterior no queremos desvirtuar el que la nueva ley de participación ciudadana promovida por el gobierno cardenista y por el Partido de la Revolución Democrática no haya impulsado una serie de mecanismos que mejoraron substancialmente la participación de los habitantes del DF, tales como el plebiscito (mediante el cual los ciudadanos pueden aprobar o rechazar actos o decisiones que someta a su consideración el jefe de gobierno); el referéndum (que permite a los ciudadanos aprobar, derogar o abrogar leyes expedidas por la Asamblea Legislativa); la iniciativa popular, la consulta vecinal y la colaboración vecinal. Junto a esto, el principal acierto de la ley fue que buscó expresar con todo cuidado a las identidades colectivas básicas socio-culturalmente hablando, las fronteras sociales autodefinidas (los comités vecinales).

Sea como sea, es obvio que las demandas bien jerarquizadas y consensadas de 30 comités vecinales son defendibles con más fuerza por la ciudadanía y a su vez la experiencia nos enseña que la administración responde mucho más eficazmente a estos ordenamientos que a la demanda dispersa y mal organizada de 150 comités que en promedio componen cada una de las delegaciones políticas del DF (ello no implica, evidentemente, que deban descentralizarse con los mismos parámetros muchos servicios urbanos y grandes obras hidráulicas, bomberos, muchos niveles de salud y, menos aún, la planeación sobre el uso del suelo y el crecimiento de la mancha urbana y otros asuntos por el estilo que exceden con mucho la responsabilidad de una unidad subdelegacional).

Porto Alegre en el Brasil, con un poco más de un millón de habitantes (tan grande como una delegación del D.F.), fue dividida en cerca de dieciseis zonas, buscando que el número de consejeros no excediera a las cuatro decenas y que el trabajo resultara lo más eficaz posible. Además, solamente en una época del año los consejeros se reúnen en ese plano más centralizado del consejo municipal; la mayoría del tiempo esos consejeros, incluso antes de ser elegidos, permanecen discutiendo los problemas en espacios muy descentralizados, muy enraizados en el nivel vecinal, en la pequeña región, en la colonia o conjunto de colonias con problemáticas homogéneas.

\section{LA DIFÍCIL TAREA DE ENCONTRAR EL JUSTO MEDIO}

Enumeremos entonces los factores que impidieron incorporar en la nueva Ley de Participación un nivel de agregación intermedio, entre el de la unidad vecinal (o el comité vecinal) y el de la Delegación Política:

1. La sociedad encadenada a la política. Desde el inicio de su gestión la administración perredista aceptó encadenar la discusión de la nueva Ley de Participación Ciudadana (cuya aprobación dependía del parlamento de la ciudad, la Asamblea de Representantes, con amplia mayoría del PRD), a la discusión sobre la Reforma Política del Distrito Federal (reforma supeditada los órganos legislativos federales con clara mayoría priísta). Hasta cierto punto era comprensible el intercambio ya que era indispensable poner en claro si el Distrito Federal pasaría a ser el estado 32 de la federación, las atribuciones plenas de su cámara de representantes, el estatuto preciso de sus municipios en sustitución de las 16 delegaciones (y todas las imprecisiones de esta última figura), la manera en que serían elegidos por primera vez los delegados o presidentes municipales (ya que sólo estaba asentado que en las elecciones del año 2000 serían elegidos por voto universal y directo), las obligaciones presupuestales de la Federación hacia la nueva entidad federativa y otros tantos problemas relacionados con esta reforma política. Sin embargo, las discusiones en torno a ambas legislaciones comenzaron a dilatarse y la euforia que el triunfo de Cuauhtémoc Cárdenas podría haber proyectado hacia el tema central de campaña en torno a la reorganización participativa de los ciudadanos se perdió a lo largo del estratégico 1998, primer año de gobierno cardenista. A final de cuentas, las negociaciones en torno a la reforma política del DF no prosperaron y la Ley de Participación ciudadana fue aprobada unilateralmente por el PRD después más de un año de retraso y sin el impacto que hubiera podido tener en el inicio de la gestión. Los resultados comiciales fueron extremadamente desfavorables para el gobierno de la ciudad y descalificaron rotundamente los lemas de la campaña cardenista: si en las elecciones de 1995, acudieron a las urnas 902 mil electores, en julio de 1999 sólo asistieron 575 mil (37\% menos) '.

2. La participación enclaustrada. Todo esto trajo aparejado el que la polémica en torno a la participación ciudadana no se ligara desde temprano esencialmente a la vida barrial, a las colonias, al espacio público, sino que fuera secuestrada durante larguísimos meses en los salones cerrados del parlamento y del palacio de gobierno del DF.

3. Pulverizar: la tentación de gobernar. Sin embargo, semejante fracaso electoral no solamente se debió al hecho

1. De por sí las elecciones de 1996 no habían atraido a las urnas ni el $10 \%$ de los votantes potenciales. Véase CERvÁnTEZ DíAs, LONGORIA y TÓRREZ PÉREZ (1999): "Informe-evaluación y balance técnico de las elecciones vecinales del 4 de julio”. Partido de la Revolución Democrática. 
aparentemente simple de esta supeditación de los tiempos sociales (participación ciudadana), a los de la política (reforma política del DF), sino a las implicaciones que todo ello trajo aparejado: al transcurrir el año 1998 los partidos de oposición (particularmente el PRI con un enraizamiento territorial importante), comenzaron a exigir que la Ley de participación observara la creación de un consejo de representantes centralizado en cada delegación. El asunto tenía implicaciones políticas porque los delegados habían sido designados por el jefe de gobierno del DF mientras que los integrantes de dichos consejos tendrían la legitimidad del voto, pero sobre todo, porque cada delegado tendría un consejo de representantes vecinales (una especie de cabildo), supervizando sus actos de gobierno. El temor no era solamente hacia los partidos de oposición sin sino también hacia las propias corrientes y organizaciones sociales perredistas, que reclamaban haber ganado las elecciones y cuyas diferencias con los gobiernos locales se fueron ahondando conforme pasaba el tiempo, como es normal en todas las experiencias de gobiernos democráticos (para decirlo en pocas palabras, los movimientos y organizaciones sociales luchaban por espacios para asentar proyectos de vivienda popular, mientras que los responsables de la administración debían vigilar por que dichos proyectos respetaran las normas de uso del suelo, de densidad, viabilidad hidráulica, vialidad etc.). Hubo miedo a enfrentar a toda esa oposición y a todas esas demandas organizadas y se evitó crear un consejo delegacional, pero en el mismo impulso se borró toda instancia por encima de los comités vecinales, como pudieron haber sido los consejos sub-delegacionales.

4. Comités de seguridad: ¿espacio idóneo de la participación ciudadana? Todo este retraso, producto de las urgencias de la política por sobre la sociedad, provocó que Cuahtémoc Cárdenas, urgido por su promesa de campaña en torno a gobernar iJuntos! con la ciudadanía, decretara el inicio de los comités ciudadanos en torno al tema de la seguridad y la prevención del delito. El calculo era correcto y partía de un hecho radical: la gente no considera la participación colectiva como algo atractivo: la gente no tiende a participar sino, en la mayoría de los casos, tiende a refugiarse y a delegar sus responsabilidades en los líderes o los representantes a menos que considere que algunos de sus problemas urgentes podrían ser resueltos con ese acto colectivo de participar. En Sudamérica se inventó la modalidad de destinar un reducido porcentaje del presupuesto municipal para que las juntas vecinales, después de un proceso muy bien normado, decidieran en qué debería ser invertido. En México desde muy pronto quedó claro que el llamado a la participación ciudadana encuentra oídos entre la gente cuando está asociado al tema de la seguridad y de la delincuencia en un espacio territorial definido (¿cómo tener control sobre la policía, cómo organizar una policía de barrio eficaz, cómo construir la defensa de la colonia, el barrio...?). El problema residía en cómo servirse de esas "técnicas" de la participación conformando unidades territoriales capaces de respetar la identidad poblacional. Y es que, como decíamos, desde el momento en que la cuestión de la seguridad se destacó en las encuestas como la preocupación número uno de la ciudadanía, Cárdenas ligó inteligentemente su programa de seguridad al objetivo de la participación ciudadana: "se trata, explicó, de un programa preventivo que se basa en la descentralización, en la asignación de responsabilidades territoriales y en la convocatoria a la participación ciudadana... integrar consejos vecinales que promuevan la seguridad de las colonias... La única forma de acabar las complicidades entre policías y ladrones es establecer una instancia que vigile a ambos, y en ella el papel protagónico obviamente lo tiene la ciudadanía".

Ahora bien, pronto surgió una dificultad al tratar de articular la participación ciudadana y la seguridad: el acuerdo principal que hubo entre parlamentarios, partidos, gobierno y ciudadanos en las discusiones en torno a la nueva Ley de Participación Ciudadana fue, como ya decíamos, que la colonia, el barrio, el poblado o la unidad habitacional debían ser los espacios territorializados de identidad consistente a fortalecer ya que sólo ahí es posible hacer florecer la vida asociativa y los procesos generadores de ciudadanía. En la práctica, sin embargo, los agregados espontáneos en que los ciudadanos han comenzado a asociarse para enfrentar el problema de la inseguridad y la delincuencia tienden hacia unidades asociativas mucho más pequeñas que las antes mencionadas: en una misma unidad habitacional ellos se organizan en función del pequeño estacionamiento y las aceras que conducen al cubo exclusivo de sus departamentos (en lugar de que cinco o diez grandes edificios se asocien en torno a la seguridad); o bien, familias de clase media con viviendas unifamiliares no quieren saber nada de una pequeña unidad habitacional con la que colindan y con la que prácticamente se traslapan o, en fin, los habitantes de un conjunto de apenas cuatro cuadras se dividen en dos grupos y en lugar de dos enrejados tienen que poner cuatro, porque unos comerciantes a la mitad de ese conjunto se oponen a quedar aislados de su potencial clientela. A ese ritmo, en lugar de 30 ó 50 unidades vecinales en promedio por cada 100 mil habitantes podrían llegar a ser 500 o más microuniversos privatizantes y aislados. ¿Cuál es el sentido de esa pulverización? Sin duda el miedo, la violencia, la delincuencia y el sentido común con que el ciudadano deja de creer en la solidaridad y en las amañadas estadísticas pretendidamente tranquilizadoras.

Cuando se discute con los vecinos es muy difícil encontrar argumentos para convencerlos de que no se encierren, al menos no en espacios tan pequeños e irracionales, como los descritos, pues en el mediano plazo no tendrán dinero ni para pagar la vigilancia en el interior de sus enrejados y, además, en muchas ocasiones esos mismos vigilantes se encargan de robarlos, porque conocen con precisión el funcionamiento del microvecindario.

Estamos aquí, pues, frente al problema de cómo conciliar espacios de participación y espacios de seguridad ciudadana ya que es claro que en un caso estamos hablando de la extensión y el fortalecimiento de la vida pública y asociativa y en el otro, en la mayoría de los casos, estamos recreando fantasmas, huyendo, encerrándonos (en el extremo frente a la televisión), y que con esa actitud muy poco ayudamos a enfrentar nuestros problemas. La inseguridad es un asunto público que ha demostrado no encontrar solución si se privatiza o se individualiza. Pero también es cierto, qué 
duda cabe, que si los programas de participación ciudadana y de prevención de la delincuencia no avanzan palpablemente, como parece estar siendo el caso en el primer gobierno perredista en el Distrito Federal, los ciudadanos no tienen por qué dar crédito a supuestas soluciones que van más allá de su pequeño vecindario ${ }^{2}$.

Cuando finalmente tuvo lugar la elección de comités vecinales, éstos no se acoplaron bien en dimensiones y en preocupaciones con los comités de seguridad que los habían precedido y que tendían más al encierro que a la vida pública (no se está afirmando sin embargo que esa tendencia sea irreversible).

5. La participación "light": la visión estudiantil. Algo parecido sucedió con la cantidad de jóvenes del movimiento estudiantil de 1987, en contra de la privatización de la UNAM, que apoyaron a Cárdenas desde su campaña del 88 y que recibieron como premio, con el triunfo del 97, la Dirección General de Participación Ciudadana del Gobierno de DF. Ante el retraso del marco normativo, en lo que ellos mismos se sentían responsables, decidieron convocar a la ciudadanía a volcarse a las calles, en una modalidad que fue bautizada como participación "light" o "dominguera", y que consistía en convocar a la ciudadanía los fines de semana a remozar un parque o una gran avenida de la ciudad de principio a fin (poda, limpieza, pintura de guarniciones, señalización, etc.). Esta práctica tenía la cualidad de un mayor impacto publicitario debido a sus resultados inmediatamente palpables y constituía en sí misma un evento de masas mucho más acorde con las tradiciones del movimiento estudiantil que con el objetivo de una sedimentación lenta pero con alta continuidad que requiere la organización vecinal. En efecto, pasado el día festivo poco quedaba, aunque los estudiantes y el equipo de gobierno sí mantenían su continuidad un fin de semana tras otro.

6. La inercia del caudillo. Fue inevitable también, y ya no tanto por el retraso normativo como por la propia inercia cultural y administrativa, que los nuevos delegados políticos reprodujeran las prácticas verticales y en cierta forma lideriles, fuertemente arraigadas al patrimonialismo y al paternalismo que estaban heredando. Tuvieron que enfrentarse a audiencias públicas masivas animadas por los típicos gestores políticos, trocadores de influencia por apoyo, capaces de mezclar entre sus grupos de acarreados problemas de vivienda, de tenencia de la tierra, de seguridad, y así al infinito, en los puntos más diversos de la geografía delegacional (por decir lo menos), y reclamándose de cualquiera de las tendencias políticas, incluido naturalmente, $\mathrm{y}$ a veces predominantemente, el PRD. Otra de esas prácticas verticalistas, han sido las giras o recorridos por el territorio delegacional en las que el del delegado tiene que hacer frente a una infinidad de demandas de personas y grupos, mal presentadas, mal discutidas, mal jerarquizadas. En la medida en que no apareció por ninguna parte un órgano intermedio en donde se discutieran y ordenaran profesionalmente esas demandas, las mismas prácticas se mantuvieron y fueron absorbidas hacia ellas los nuevos equipos administrativos. Es más, la nueva Ley de Participación de 1999, sin crear los espacios intermedios, sí mantuvo sin cambio alguno las practicas descritas, como las giras y las audiencias públicas del delegado, al lado de otras de mayor fomento al asociativismo vecinal como la Iniciativa Popular, el Referéndum, el Plebiscito, etc.

7. Entre la atomización y el patrimonialismo. Sin embargo, siendo realistas, la reconstrucción de lo local, de las identidades colectivas circunscritas y con continuidad en el tiempo, enfrenta problemas: en una sociedad como la de la Ciudad de México, debido a que la severa crisis económica ha mantenido estancados los índices de crecimiento durante los últimos quince años, debido al desordenamiento social que la globalización ha acarreado y debido a los elevados índices de violencia e inseguridad ciudadana que de ahí resultan, los habitantes de este enorme conglomerado o bien se refugian en posiciones defensivas privatizantes (veíamos como colonias de clase media, viviendas unifamiliares, condominios, unidades habitacionales, fraccionamientos privados... están cerrando aceleradamente sus calles, poniendo rejas por todos lados, ensayando todos los sistemas de alarmas), o bien la creciente masa recrea de manera alarmante formas organizacionales defensivas, verticales, tributarias de un número cada vez mayor de liderazgos que supuestamente les garantizan que "alguien" se encargará de gestionar la solución de algunos de sus problemas urgentes (esta última forma organizativa se encuentra privilegiada, como es obvio, en los espacios de mayor precariedad y en los más tradicionales, que coinciden con las colonias de asentamiento relativamente reciente). Ahora bien, muchos de los comités vecinales recientemente elegidos terminaron constituyéndose en el blindaje legal de otros tantos liderazgos personalizados (caciquillos que han surgido aquí y allá como hongos y que hoy las autoridades están obligadas a atender por ley, sin que sus demandas sean mediadas, atemperadas, redimensionadas por la discusión con otros comités de la zona).

Ante la pulverización y la atomización privatizantes, de un lado, y el neo-patrimonialismo, del otro, se ven erosionados los espacios de la democracia social, aquellos que verdaderamente fortalecen el asociativismo de la sociedad civil, el verdadero embarnecimiento social.

8. La participación politizada. Finalmente, se han echado a andar los comités vecinales hacia el final del año 1999. Nos encontramos a escasos diez meses de que concluya el primer gobierno perredista del DF y, aparte de que los recursos para su fomento se encuentran extremadamente limitados, estos nuevos comités ciudadanos inician sus funciones cuando arrancan los seis meses más intensos de la política nacional, pues a mediados del año 2000 habrá elecciones presidenciales, de las cámaras federales, del jefe de gobierno y de la Asamblea Legislativa del DF. Esto quiere decir que la participación ciudadana (social) dará inicio cuando

2. Los datos son aplastantes: si es cierto que la delincuencia denun ciada entre 1993 y 1996 se multiplicó $80 \%$ en el Distrito Federal y $92 \%$ en el resto de la República y que solamente 29 de cada mil delitos registrados (3\%) en 1996, terminaron con la captura del presunto responsable y su presentación ante un juez penal (Rafael RUIz HARREL, "La zona metro politana, un reporte”, Reforma, 21 de octubre 1996, p. 2b), entonces, en efecto, todo se estaría acercando a un escenario des-institucionalizante por llamarlo de alguna manera, en donde los ciudadanos individualmente no tienen ninguna fuerza, los contratos no cuentan con ningún respal do que los haga respetables y, en una palabra, el principio civilizatorio estaría siendo debilitado. 
todo el interés estará puesto en la esfera de la política. Lo anterior podría convertir a muchos comités ciudadanos en promotores del voto partidista y con ello se vería desvirtuado el objetivo de otorgar a la ciudadanía un instrumento de "empoderamiento" social, no para hacer política sino frente a la política y los aparatos de poder.

\section{CONCLUSIONES}

Ahora bien, si lo ideal es, según lo hemos establecido en este artículo, el que los espacios subdelegacionales o comités zonales se conviertan en el lugar de confluencia de un conjunto de comités vecinales y ahí se discutan, ordenen y jerarquicen sus demandas, lo cierto es que tampoco existen muchos ejemplos en los que pueda ser probada esta aseveración. Con lo reciente y lo deficiente de la legislación al respecto, y debido a la bajísima participación de los ciudadanos del DF en las elecciones vecinales, los pocos experimentos parecidos a un consejo zonal que se han llevado adelante, han debido ser conformados de manera muy mezclada para lograr alguna representación ciudadana. Se han tenido que combinar así, al lado de los comités vecinales, organizaciones sociales, políticas, culturales, etc., con presencia destacada en esos territorios. A los comités vecinales se les está empujando para ocupar poco a poco el centro de la escena, pero la mayor capacidad organizativa y de convocatoria sigue dándose en torno a los organizaciones con tradición y eso nos ha convencido de que durante un periodo muy prolongado, los comités zonales trabajarán virtualmente bajo esta forma mixta de representación.

En los pocos ejemplos que han sido animados, algunos de ellos en la delegación Tlalpan, los comités o consejos zonales, como también los hemos llamado, han sido integrados igualmente por grupos o personas que actúan como consultores externos, cuya función ha sido esencialmente profesional en torno al desarrollo urbano, la seguridad, los servicios urbanos, etc. (las ONG's COPEVI y FOSOVI han integrado esos consejos con gran regularidad). Todos esos ejemplos han estado articulados, en los últimos dos años a los veinte Planes Parciales ordenados por la Secretaría de Desarrollo Urbano y Ecología del gobierno central del DF, y que puso en relación a este organismo con las consultoras y ONG's para cada plan parcial, personal de las Delegaciones Políticas, comités vecinales y organizaciones sociales de áreas bien delimitadas territorialmente. Importantes enseñanzas sobre la participación se han derivado de los trabajos en torno a los planes parciales de desarrollo urbano, ya que como es lógico suponer, dichos planes fueron establecidos en aquellas colonias y pueblos en donde el desarrollo urbano se ha tornado crítico en términos de usos del suelo y organizaciones sociales y políticas.

Estos consejos funcionan en muchos momentos con la presencia de las autoridades y profesionales del gobierno, de manera que los subdelegados de obras, servicios urbanos, desarrollo social, cultura, desarrollo económico, etc., pueden, en fechas precisadas de antemano y limitadas en el tiempo, presentar y recibir proyectos de inversión, hacer y recibir propuestas presupuestales y llegar a consensos con las otras propuestas ciudadanas presentadas por los integrantes del consejo en el nivel de detalle de costos, tramos precisos de obra, calidad de los materiales y los servicios que deberán ser empleados o contratados etc. A la larga se buscaría que los programas surgidos de los consejos zonales puedan ser aprobados por el gobierno delegacional (municipal), y que incluso una parte del presupuesto de las obras pudiera ser administrado en ese nivel. Todo esto implica que la actividad de un comité zonal pueda y deba ser dividido en mesas de trabajo especializadas en las distintas problemáticas que aquejan esa unidad territorial. Si un problema es muy grave es obvio que el consejo en su conjunto se transformará en el comité en torno a dicho tema: seguridad y delincuencia; agua; servicios urbanos; regularización territorial; juventud, recreación y deporte...

Hacemos estas referencias a la participación en el Distrito Federal porque no contamos con muchas más, y por las enseñanzas que de ahí hemos desprendido. En esos ejemplos se ha puesto de manifiesto la tensión creciente en que se está desarrollando el quehecer de la llamada democracia representativa, frente de la democracia social (aquella que permitiría a los ciudadanos, en persona o en grupos, expresar sus demandas, críticas o apoyos a las iniciativas legislativas o a los actos de gobierno, sucesos, o situaciones diversas que consideren que los implican o los afectan). En épocas tan dramáticas como la que está viviendo nuestro país, en las que no sólo la pobreza creciente sino también la movilidad y el cambio acelerado desorganizan y pulverizan a los agregados naturales de ciudadanos en sus barrios, en sus colonias y en sus pueblos, es lógico constatar esta tensión entre democracia representativa y democracia social. Debemos construir seriamente el espacio de la ciudadanía, debemos aceptar que la organización social no es un simple preámbulo, un pretexto para la influencia de los aparatos de la política. Se trata de un piso social diferente al de los partidos y al del parlamentarismo, un plano que no debiera ceñirse nunca, por naturaleza, a ninguna manipulación gubernamental. La participación ciudadana no debería ser, en resumen, una vía de ascenso al poder político sino su contrapeso.

Agreguemos en fin, que la participación ciudadana en el DF se encuentra en un momento crucial. En efecto, en octubre del año 2000 entrará una nueva administración al gobierno de la ciudad capital. El candidato del PRD, con amplias posibilidades de darle continuidad a los primeros tres años de gobierno de este partido, se ha expresado ampliamente sobre el tema en el inicio de su campaña. "La primera iniciativa de ley que enviaré a la Asamblea, ha dicho, será la de convertir los actuales comités vecinales en gobiernos ciudadanos, en gobiernos de la gente... (Los mil trescientos comités vecinales) tienen facultades limitadas, sólo se ocupan de gestiones y trámites. Por eso, los transformaremos en gobiernos vecinales. Es decir, vamos a crear la cuarta instancia de gobierno..., mil trescientas unidades con representantes electos democráticamente por sus vecinos y con personalidad jurídica y presupuesto propio..: recursos y atribuciones para aplicar programas de desarrollo social, dar mantenimiento a obras y servicios públicos, como reponer una rejilla en la calle, tapar un bache, cambiar una luminaria, pintar una escuela mejorar los jardines, cuidar árboles, 
cuidar y mejorar las áreas verdes. Bajo su mando estará la policía preventiva, con la intención de integrar a la comunidad y hacerla más eficaz en su función de garantizar la seguridad pública a los ciudadanos... Se trata de no generar burocracia, que rindan cuentas, que manden obedeciendo y que sea la asamblea de ciudadanos la máxima autoridad" ".

Estas son las intenciones del nuevo gobierno y queda abierta la discusión: es obvio que, al menos hasta el día de hoy, habiendo votado por dichos comités menos del 10\% de la ciudadanía y siendo muchos de ellos tan endebles, podría ser un poco excesivo el cargarlos con un exceso de atribuciones y con la responsabilidad del manejo presupuestal. Nos parece sin embargo que es un gran avance el que la campaña del PRD coloque en posición tan destacada el asunto de la participación ciudadana. Es cierto también que es indispensable aprovechar la primera etapa de un gobierno, el momento de mayor euforia, para hacer que las personas participen. De ahí que sea urgente complementar el plan que hemos citado en los párrafos anteriores con una discusión seria sobre la posibilidad de las instancias intermedias y los comités mixtos (evitando la pulverización de los mil trescientos comités), tal como lo hemos presentado en este ensayo.

\section{SIGLAS}

ALDF Asamblea Legislativa del Distrito Federal.

COPEVI Centro Operacional de Vivienda y Poblamiento A.C. (ONG).

DF Distrito Federal (La entidad capital de la República Mexicana.

FOSOVI Fondo Social para la Vivienda (ONG)

PRD Partido de la Revolución Democrática.

PRI Partido Revolucionario Institucional.

UNAM Universidad Nacional Autónoma de México.

3. Discurso de Andrés Manuel LóPEZ OBRADOR en la toma de protesta como candidato a Jefe de Gobierno del Distrito Federal del PRD, 5 de diciembre de 1999, Revista Memoria, N. ${ }^{\circ} 131$, enero del 2000.

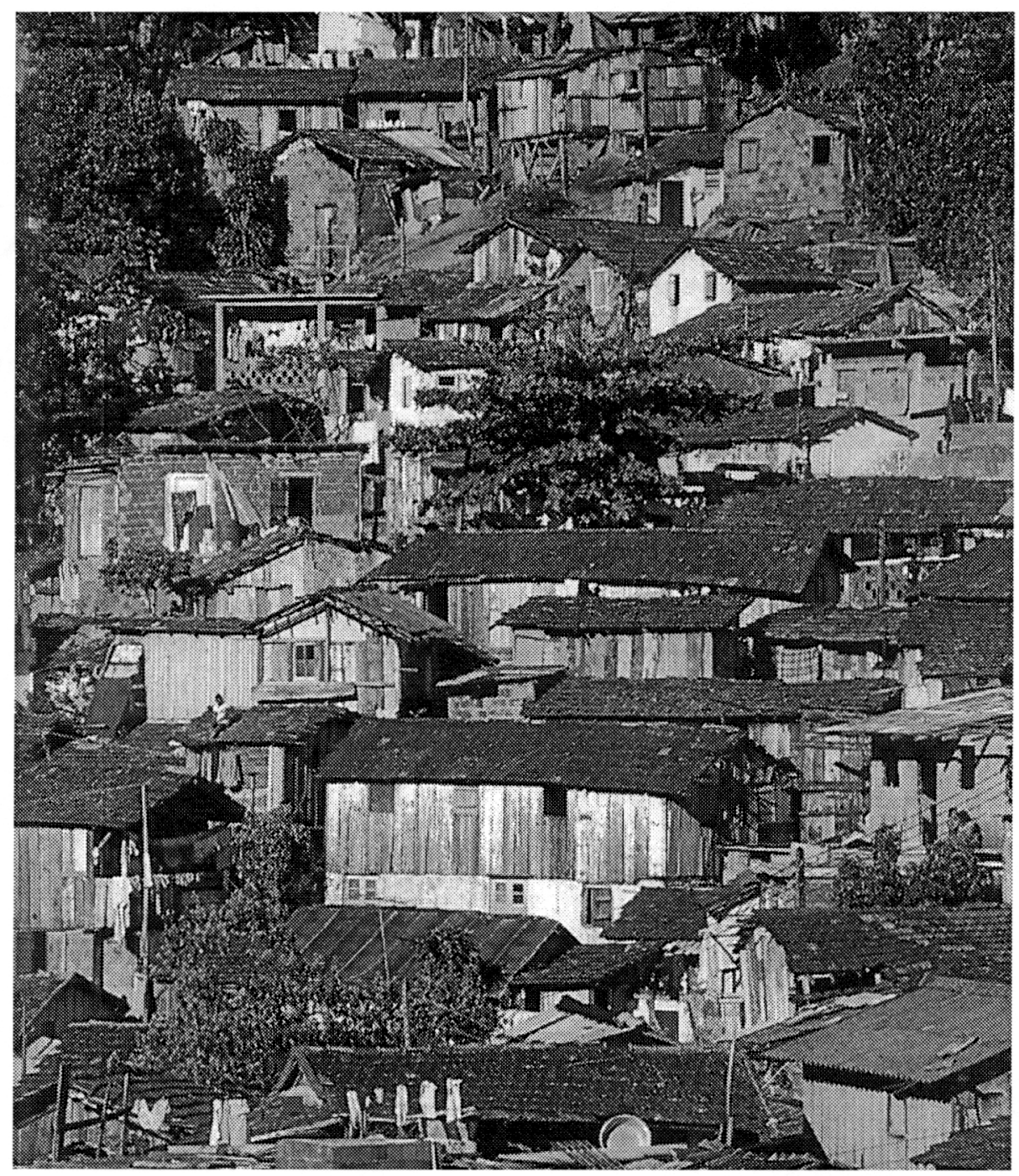

